\title{
RECENT ADVANCES AND METHODS FOR IN-VITRO EVALUATION OF ANTIDIABETIC ACTIVITY: A REVIEW
}

\author{
Ms. Aher Pratiksha R. \\ Department of Quality Assurance Techniques
}

\begin{abstract}
The antidiabetic properties of synthetic or natural substances can be evaluated by in -vitro methods such as study of glucose uptake, effect on glycosylation of the hemoglobin and inhibition of alpha amylase, alpha glucosidase and sucrase enzymes. The inhibitory nature of a test compound on alpha amylase enzyme reflects the antidiabetic activity because of unavailability of glucose from gastrointestinal tract. Alpha-glucose inhibitor reduces the impact of glucose on blood sugar and hence alpha glycosidase inhibitors can be considered as oral antidiabetic drugs. Once a hemoglobin molecule is glycated, because of high blood glucose level, it remains that way. Hence the estimation of glycated hemoglobin is important tool in the antidiabetic screening procedure. The inhibition of such glucose uptake by yeast cell is an important tool for the evaluation of antidiabetic property. Glucose diffusion assay is a simple diffusion method to evaluate the glucose movement in vitro and is expressed in terms of glucose diffusion retardation index (GDRI). In vitro technique like cell culture is one of the important methods to evaluate the activity. Level of insulin secretion in culture of HIT-T15 cells is also reported for evaluation of antidiabetic activity.
\end{abstract}

Keywords: Alpha amylase; alpha glucosidase; sucrose inhibitory activity; pharmacological screening

\section{INTRODUCTION}

With Advances in the field of medicinal technology for eradicating the communicable disease, keen awareness is focused to ease the burden of noncommunicable disease ${ }^{1}$. It is predicted that, by 2020, non-communicable diseases such as diabetes mellitus and cancer will cause seven out of every ten deaths in developing countries. An increase in the diabetic individuals or with a longer duration of diabetes alters the disease profile globally, which is due to a prevalence of diabetes associated secondary complications, such as nephropathy and peripheral arterial disease. ${ }^{2}$

\author{
Mr. Thete Ajinkya Dilip \\ Department of Instrumentation and Control
}

Diabetes is a disease in which the body does not produce or properly use insulin, which results in elevated blood sugar levels, a condition classically called as diabetes. The body needs insulin to convert sugar, starch and other foods into energy. Major symptoms of this disease are polydipsia, polyuria, weight loss etc. Several antidiabetic drugs such as alpha glycosidase inhibitors, sulfonylurea and biguanides derivatives are available in market, which have different pharmacological actions. No single drug is available as complete remedy to this. Several side effects are produced by the existing drug. The mentioned drugs produce several side effects such as abdominal pain, weight gain, vomiting, diarrhea, headache, dark urine, fluid retention, allergic reaction, hypoglycemia etc. Researchers are focused to develop the safer and single remedy for diabetic disorder. To evaluate the antidiabetic activity of synthetic or natural compound (isolated from traditional plants) in-vitro and in-vivo methods are used. $3-8$

The antidiabetic properties of synthetic or natural substances can be evaluated by in -vitro methods such as study of glucose uptake, effect on glycosylation of the hemoglobin and inhibition of alpha-amylase and alpha-glucosidase enzymes. The present scenario of pharmacological screening involves testing of new chemical entities as extract from plant or any material (synthetic/semisynthetic) in isolated preparations followed by tests in whole animals. Rats, mice and sometimes higher animals like monkeys and dogs are used. Most drugs in use nowadays at therapy have been developed with these methods. Non-animal alternatives are advisable wherever necessary. The challenge for pharmacologist always will be to correlate in-vitro data with in- vivo findings. A key goal in pharmacological screening is a good understanding of the in-vitro performance. The current review focuses the various in-vitro methods for the evaluation of antidiabetic activity. In-vitro methods can play a very important role in the screening of antidiabetic activity of drugs and avoid or restrict animal use.

\section{Alpha glucosidase inhibitory activity}

Alpha-glucose inhibitor reduces the impact of 


\section{International Journal of Engineering Applied Sciences and Technology, 2020 Vol. 4, Issue 9, ISSN No. 2455-2143, Pages 194-198 \\ Published Online January 2020 in IJEAST (http://www.ijeast.com)}

glucose on blood sugar. Hence alpha glycosidase inhibitors are employed as oral antidiabetic drugs. Alpha-glucosidase inhibitors are saccharides that act as competitive inhibitors of carbohydrate digesting enzymes, specifically Alpha-glucosidase enzymes in the brush border of the small intestines. In this method, different concentration of sample solution is incubated with 10 milliliters of enzyme solution for 10 minutes at $37^{\circ} \mathrm{C}$. Maleate buffer $\mathrm{pH}$ 6.0 solution is used to make the volume. The enzyme reaction is started by adding solution of $\mathrm{p}$ nitrophenyl alpha D-glucopyranoside and further incubated $37^{\circ} \mathrm{C}$ for $30 \mathrm{~min}$. The reaction is terminated by treating the mixture in boiling water bath for $5 \mathrm{~min}$. After the addition of $0.1 \mathrm{M}$ disodium hydrogen phosphate solution the absorbance of liberated p-nitrophenol is read at $400 \mathrm{~nm}$.

\section{Evaluation of hemoglobin glycosylation}

Glycation of protein frequently occurs, but in the case of hemogloblin a non-enzymatic pathway occurs between glucose and the $\mathrm{N}$ end of beta chain. In this method, blood from healthy volunteers is placed into a bottle containing anticoagulant. Then blood is mixed with sodium chloride and one volume of carbon tetrachloride for the preparation of hemosylate according to hypotonic principle. The resulting hemolysate may contain debris, which is removed by centrifugation at higher rpm for 15 minutes at room temperature. The hemoglobin rich fraction is concentrated in the upper layer. One milliliter of hemoglobin fraction is transferred to test tube containing different concentration of glucose solution. Gentamycin $(0.02 \%)$ and different concentration of test solution are added to the above mixture. All these solutions should be prepared in phosphate buffer. The reaction mixture is kept under incubation for 72 hours at $25^{\circ} \mathrm{C}$. At different interval of incubation, the glycated hemoglobin is determined by spectrophotometry.

\section{Alpha amylase inhibition}

Alpha amylase enzyme is responsible for the hydrolysis of alpha bond linked polysaccharides such as starch and glycogen to disaccharides. Hence the inhibitory nature of the test compound reflects the antidiabetic activity because of unavailability of glucose from gastrointestinal tract. Figure 1 shows a diagrammatic representation of mechanism of action of $\alpha$ amylase. Alpha amylase inhibitors bind on alpha bonds on polysaccharides and prevent the conversion of polysaccharides to disaccharides and monosaccharides. 7,8 The method involves mixing the sample with starch solution in beaker, adding alpha amylase to this mixture, stirring vigorously and finally incubating at $37^{\circ} \mathrm{C}$ for one hour. After incubation, $0.1 \mathrm{M}$ sodium hydroxide is added to terminate the enzyme activity. The mixture is then centrifuged for $15 \mathrm{~min}$ and the glucose content in the superficial layer is determined by measuring the absorbance of coloured solution at $565 \mathrm{~nm}$.

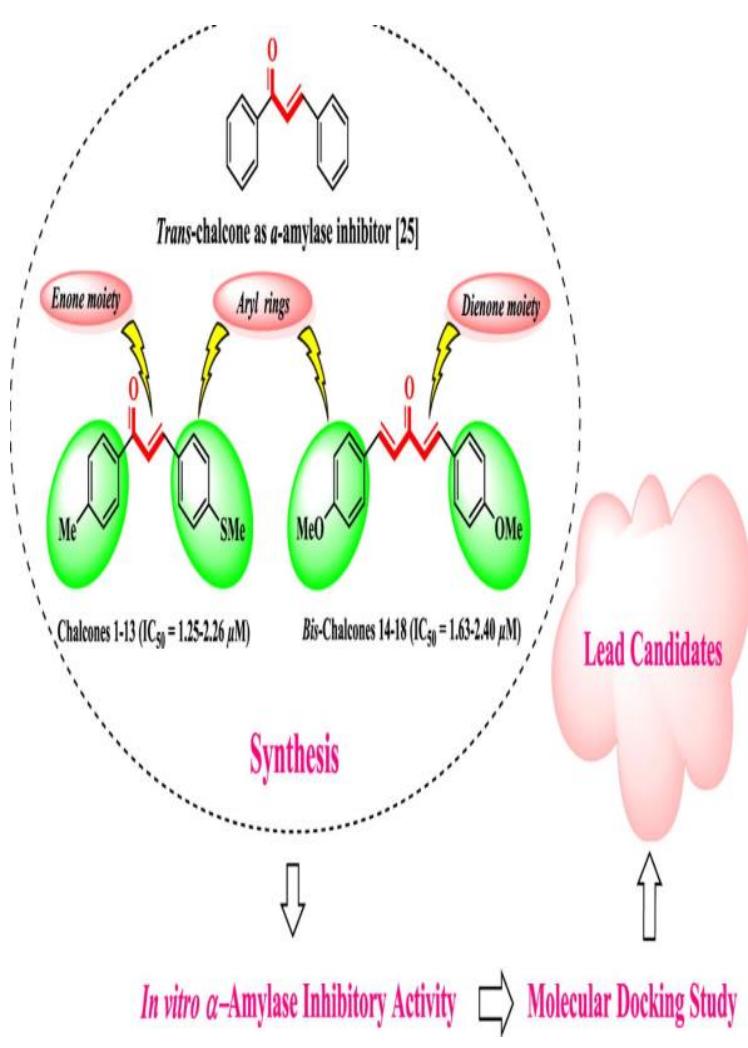

Figure 1 : Diagrammatic representation of mechanism of action of $\alpha$ - amylase.

\section{INSULIN SECRETION IN CULTURE OF HIT-T15 CELLS}

HIT-T15 cells are seeded into collagen coated sterile 96 good plate at density of cell per well. After 24 hours recovery period, the cells are washed with appropriate buffers. Then preincubation is carried out in the same buffers for 30 minutes at $37^{\circ} \mathrm{C}$. The buffer is then removed. Prepare different concentration of standard drugs like glibenclamide and then add to the wells. Incubate the cell for $1 \mathrm{~h}$ at $37^{\circ} \mathrm{C}$. The supernatant is collected and the released insulin is measured using ELISA test.

In vitro anti-hyperglycemic activity screening by starch-iodine color assay

Figure 2 shows a diagrammatic representation of in vitro anti- hyperglycemic activity by starch -iodine colour assay. This assay is based on the slight modification of starch-iodine test. Various 
concentrations of test solutions are prepared and incubated with alpha amylase containing sodium phosphate buffer ( $\mathrm{pH}$ around 6.9 containing sodium chloride) at $37^{\circ} \mathrm{C}$ for 10 minutes. Soluble starch solution $(1 \%)$ is added to each reaction well and incubated at $37^{\circ} \mathrm{C}$ for 15 minutes. Hydrochloric acid ( $1 \mathrm{M})$ is added to stop the alpha amylase action followed by the addition of iodine reagent. The color change is noted and the absorbance at $660 \mathrm{nM}$ is read in a microplate reader. The same procedure is repeated with control.



Figure 2: In vitro anti- hyperglycemic activity by starch -iodine colour assay

\section{Model to study insulin secretion from beta cells of the pancreas}

The HEPG2ins/g cells are used to study insulin secretion from beta cells of the pancreas. This cell line is also called as betacyte, which is genetically engineered insulin-secretary human liver cells line. ${ }^{9-11}$ The insulin secretary HIT cell line is developed by isolating pancreatic islets from in hamster dispersing the islets into single cells, transforming the cell isolates with the Simian virus 40(SV40), and cloning out the insulin secretary cell lines. Experiments for assessment of glucose transport activity in HTT cells and western blot analysis for GLUT2 in these cells after incubation with glibenclamide and troglitazone were performed by Masuda et al. ${ }^{12}$

\section{Model to study inhibitors of intestinal glucose uptake}

The determination of insulin based on the stimulation of glucose uptake by the isolated diaphragm form mice and rats has been used by many investigators to study the effects of insulin and insulin-mimetic substance on muscle tissue.

Intact washed rat diaphragms are incubated (for 30 minutes at $37^{\circ} \mathrm{C}$ ) in HEPES-buffered saline under constant bubbling with $95 \% \mathrm{O}_{2}$ and $15 \% \mathrm{CO}_{2}$. The diaphragms are then washed two times with the same buffer lacking glucose and further incubated (30 min) in $5 \mathrm{~mL}$ of glucose free buffer in the presence of test compounds or insulin. Glucose transport is initiated by addition of $10 \mathrm{mM} 2(1-3 \mathrm{H})$ deoxyglucose in the absence of presence of $25 \mathrm{DM}$ cytochalasin B (control) After $15 \mathrm{~min}$ the diaphragm are rinsed 4 times with icecold buffer containing $10 \mathrm{mM}$ glucose $25 \mathrm{DM}$.

\section{Model based on muscle as an insulin target tissue}

The effect of insulin on glucose uptake in the soleus muscle of rats during hemorrhagic shock has been studied. Adipocytes are incubated with D(U-14C) glucose $(0.2 \mathrm{mM}$ final concentration) for $20 \mathrm{~min}$. Cells are separated from the medium by centrifugation on silicon oil, removed and counted for radioactivity. The assay measures the total insulin-stimulated glucose uptake (signal cascade, glucose transport and glucose metabolism) irrespective whether the glucose is utilized via the oxidative or non oxidative pathway. Conversion into lipids, glycogen or membrane-impermeable intermediary products (glucose-6-phosphate) will be detected. Adipocytes are incubated with trypsin $\left(4 \mathrm{mg} / \mathrm{mL}\right.$ ) for $15 \mathrm{~min}$ at $4^{\circ} \mathrm{C}$. Soya bean is added to the mixture as trypsin inhibitor. The cells are washed thrice by flotation and used for determination of total uptake glucose. This assay measures the total glucose uptake into cells with inactivated insulin receptor. The first step in the insulin signal transduction cascade (binding of insulin to its receptor) will provide positive results.

\section{CONCLUSION}

The antidiabetic properties of can be evaluated in vitro by several methods such as study of glucose uptake, effect on glycosylation of the haemoglobin and inhibition of alpha glucosidase and alpha amylase enzymes.

\section{ACKNOWLEDGEMENT}

We thank anonymous reviewers for their critical reading and comments for improving the manuscript. 


\section{REFERENCES}

1. Schwamm LH. (2018); The communicable nature of non-communicable diseases. The Lancet Neurology.(pp.665).

2. Harding JL, Pavkov ME, Magliano DJ, Shaw JE, Gregg EW(2019); Global trends in diabetes complications: a review of current evidence. Diabetologia. (pp. 3-16).

3. Nair SS, Kavrekar V, Mishra A.(2013); Evaluation of in vitro antidiabetic activity of selected plant extracts. Int J Pharm Pharm Sci Invent. (pp. 12-9).

4. Jijith US, Jayakumari S. www. ijrap. net.

5. Tundis R, Loizzo MR, Menichini F. (2010); Natural products as $\alpha$-amylase and $\alpha$-glucosidase inhibitors and their hypoglycaemic potential in the treatment of diabetes: an update. Mini reviews in medicinal chemistry. (pp. 315-31).

6. Abideen S, Sankar M.(2015); In-vitro Screening of Antidiabetic and Antimicrobial Activity against Green Synthesized AgNO3 using Seaweeds. J Nanomed Nanotechnol S6-001.(pp.2157-7439).

7. Rotshteyn Y, Zito SW.(2004) Application of modified in vitro screening procedure for identifying herbals possessing sulfonylurea-like activity. Journal of ethnopharmacology. (pp. 33744).

8. Gupta SK.(2004); Drug screening methods. Jaypee Brothers.

9. Simpson AM, Tuch BE, Swan MA, Tu J, Marshall GM. (1995); Functional expression of the human insulin gene in a human hepatoma cell line (HEP G2). Gene therapy. (pp.223-31).

10. Tuch BE, Beynon S, Tabiin MT, Sassoon R, Goodman RJ, Simpson AM.(1997); Effect of $\beta$-cell toxins on genetically engineered insulin-secreting cells. Journal of autoimmunity. (pp. 239-44).

11.Chaudary IH, Sayeed MM and Baue AE.(1975); The effect on insulin on glucose uptake in Soleus Muscle during hemorrhagic shock.Can J Physiol Pharmacol. (pp. 67-73).

12. Masuda K, Okamoto Y, Tsuura Y, Kato S, Miura T, Tsuda K, Horikoshi H, Ishida H, Seino Y. (1995); Effects of troglitazone (CS-045) on insulin secretion in isolated rat pancreatic islets and HIT cells: an insulinotropic mechanism distinct from glibenclamide. (pp. 24-30). 
International Journal of Engineering Applied Sciences and Technology, 2020 Vol. 4, Issue 9, ISSN No. 2455-2143, Pages 194-198

Published Online January 2020 in IJEAST (http://www.ijeast.com) 